\title{
ECONOMÍA SOCIAL Y SOLIDARIA: PARADOJAS DE LA “MONEDA SOCIAL”
}

\author{
Susana R. Presta \\ Liliana S. Landaburu ${ }^{2}$
}

Resumen: En el presente artículo nos proponemos discutir sobre los alcances y límites de las iniciativas de la economía social y solidaria, producto de la crisis socioeconómica que se agudiza a partir de la década del 90 consideradas en tanto "alternativas" al sistema capitalista. De hecho, las estructuras de la economía social y solidaria no existen escindidas de las estructuras del sistema económico capitalista. En este sentido, resulta necesario reflexionar en torno a la existencia de una moneda social y sus implicancias socioeconómicas. Asimismo, nos preguntamos si es posible hablar de una racionalidad alternativa a la racionalidad capitalista o se trata de una racionalidad dependiente.

Palabras claves: Economía Social y Solidaria, Moneda Social, Racionalidad Económica, Economía Capitalista.

Abstract: In this article, we propose to discuss the accomplishments and the limits of the social and solidary economy's initiatives, as a result of the socioeconomic crisis that became worse al the $90^{\text {th }}$, which are considered as an "alternative" to the capitalist system. In fact, the social and solidary economy's structures do not exist separate from the capitalist economic system's structures, therefore it is necessary to reflect on the existence of the social money and its social and economical implications. Also, we inquire if it is possible to talk about an alternative rationality to the capitalist one or it is only a dependient rationality.

Keywords: Social and Solidary Economy; Social Currency; Economic Rationality, Capitalist Economy.

\footnotetext{
${ }^{1}$ Doctora en Antropología de la Universidad de Buenos Aires. Especialista en Filosofía Política (UNGS). Investigadora Asistent del CONICET.

${ }^{2}$ Doctora en Antropología de la Universidad de Buenos Aires.
} 
$\mid 142$ |

Economia social y solidaria:...

\section{Introducción}

A partir de la década del '70 tuvo lugar una creciente transnacionalización tanto del capital como de la producción, a partir de la cual Argentina sufrió profundas transformaciones que desestructuraron el mercado de trabajo extendiendo distintas formas de precarización laboral. Muchas industrias desaparecieron, aumentaron las prácticas oligopólicas de fijación de precios y la división de mercados.

La profundización de dicha crisis socioeconómica en los 90, ha revitalizado los preceptos de la Economía Social dando lugar a distintos tipos de emprendimientos sociales y cooperativos que intentan construir distintos proyectos de vida colectivos.

Según Coraggio (1992), la economía solidaria o de la solidaridad se fundamenta sobre formas de solidaridad ancladas en el trabajo de los beneficiarios, mas también se complementa con donaciones obtenidas a partir de proyectos de promoción de la economía popular. Depende principalmente de las donaciones y de una cultura de valores alejados del consumismo y el lucro. La economía solidaria se vincula con el concepto de empresa social, es decir, "los emprendimientos que no sólo producen mercancías sino que "producen sociedad" o lo social (formas sociales, instituciones y pautas de comportamiento)" (Coraggio, 1992: 114). Las empresas sociales se caracterizan por generar un valor social agregado ya que invierten en las capacidades de las personas. Asimismo, esta corriente realiza una crítica al asistencialismo y perciben al mercado como un posible instrumento de integración y emancipación ante la alternativa asistencialista.

Contrariamente a estoúltimo, consideramos que no podemos ubicar a la economía social y solidaria como una "alternativa" al capitalismo, sino que resulta necesario que sea estudiada desde un enfoque que nos permita analizar las complejas relaciones que se establecen entre las unidades domésticas involucradas y el mercado.

En el presente artículo estudiaremos una iniciativa que comienza con un grupo de familias en Capilla del Monte 
(Provincia de Córdoba, Argentina) que se hallaban insatisfechas con la propuesta pedagógica de las escuelas de la zona. Este grupo de familias se basó en la propuesta pedagógica de las hermanas Cossettini y el maestro Luis Fortunato Iglesias. Se trata de una pedagogía que enfatiza en el niño por medio de la educación por el arte, el compromiso social y ambiental. En este sentido, lo esencial es desarrollar la conciencia social del niño y luchar contra el egoísmo y los prejuicios. Por este motivo, los valores fundamentales se basan en la cooperación, la ayuda mutua, el compañerismo y la responsabilidad. El hecho fundacional fue una reunión realizada en Capilla del Monte, a partir de la cual seis familias aceptaron la propuesta. En el año 1997, Ramón Mestre, gobernador de la provincia, comenzó a cerrar todas las escuelas públicas rurales, reducir el número de docentes en cada establecimiento y cerrar los jardines de cuatro años en toda la provincia ${ }^{3}$. En un contexto de descontento social, la escuela se fundó en 1998. Esta última, se conformó como una Cooperativa de Provisión de Servicios Educativos y no otorga títulos oficiales ya que no adhiere al plan oficial de enseñanza. Desde sus comienzos, las relaciones con el pueblo de Capilla del Monte no fueron las mejores ya que los consideraban, entre otras cosas, como una "secta". En consecuencia, trataron de legitimar el emprendimiento por medio de distintas relaciones con otras instituciones.

En los años 1999 y 2000 participaron en el Plan de Desarrollo Integral de Capilla del Monte (organizado por el Municipio y el Ministerio de Desarrollo Social de la Nación). Todas las organizaciones sociales participaron en talleres de diagnóstico en distintas áreas: economía, educación, grupos vulnerables, ecología, entre otras. Los problemas más graves que azotan a Capilla del Monte son el alcoholismo, desempleo, violencia familiar y medio ambiente. Más del 50\% de la población pedía el "bolsón" (bolsa con alimentos) a la Municipalidad. Asimismo, cuenta con un Área de

\footnotetext{
${ }^{3}$ La cuestión central de la noción de racionalidad es la correspondencia entre lo económico y lo no económico. Es decir, no existe una racionalidad económica "en sí" ni una forma "definitiva de racionalidad económica" (Godelier, 1974).
} 
Extensión para abarcar al sector social más debilitado (el edificio fue cedido por la Municipalidad). Las actividades de esta última incluyen un convenio de educación a distancia con la Universidad Nacional del Litoral, apoyo escolar, capacitaciones gratuitas para organizaciones sin fines de lucro, espacios de convivencia y aprendizaje. En año 2001, comienzan a vincularse con escuelas de gestión comunitaria o gestión social o cooperativas (escuelas que no son públicas ni privadas) con el fin de hacer visible su forma de hacer escuelas, es decir, democráticas, inclusivas, innovadoras, de la comunidad. Para lograr este tipo de relaciones participaron en un concurso internacional de pequeñas donaciones del Banco Mundial. El proyecto presentado proponía la realización de un Congreso para este tipo de escuelas a nivel nacional (fueron premiados con U\$S 2500). En el Congreso se discutió cuál era la clave de la inclusión, de la innovación y la calidad (asistieron más de 70 instituciones). A fines del 2003, presentaron un proyecto en Universidad Católica de Córdoba para generar una capacitación en comunicación institucional con objetivo de generar una agencia de noticias del Banco de Horas Comunitario ("Chasqui de Noticias Solidarias").

Después del primer año de la escuela entendieron que no podía superar una cuota de $\$ 20$ ya las familias no podían pagar una suma mayor. Entonces, además de los \$20, decidieron producir entre todos dulces, empanadas, entre otras cosas. Mas, comprobaron que esto último no era suficiente. En 1999, surge la propuesta del Banco de Horas, pues se necesitaba disponibilidad y capacidad de trabajo para sostener una organización. De este modo, desarrollan una moneda social a la cual denominan "Soles" (Solidaridad Organizada Libre y Laboriosamente). En el segundo año comprobaron que el sistema funcionaba con una moneda propia respaldada con trabajo que apoyaba una causa común.

La Cooperativa Educacional cuenta con 15 personas trabajando. Las familias asociadas sólo hacen "changas" (trabajo en negro, subempleo). El Banco de Horas les ofrece un mercado alternativo donde pueden intercambiar productos y servicios sumados a la posibilidad de enviar a sus hijos a la escuela. De este 
modo, según el presidente del Banco de Horas, este capitaliza el valor humano y lo convierte en valor económico a favor de una causa: la escuela. Actualmente la cuota de la escuela es de $\$ 50$ y 35 soles (en su equivalente en trabajo). Aproximadamente 50 chicos y 30 familias están asociados a la cooperativa, los cuales reciben servicios de educación formal. En general, las familias que envían a sus hijos a la escuela no son originarias de Capilla del Monte y junto a los asociados al Banco de Horas Local (más de cien) permiten sostener la causa socioeducativa. Asimismo, 120 chicos reciben educación complementaria y 35 jóvenes de entre 15 y 25 años de edad asisten a tres talleres de formación laboral integral (jardinería, producción de hongos comestibles, cerámica artesanal y utilitaria). Se busca una inserción laboral o llevar adelante empresas sociales asociadas al Banco de Horas.

La economía doméstica, la cual se constituye como base de la economía solidaria, plantea otros modelos de racionalidad, producción, intercambio, distribución y consumo. En general, encontramos una escisión entre una racionalidad económica orientada a la maximización de la ganancia, la organización capitalista de la producción, la circulación y consumo de bienes y servicios y aquella orientada a la reproducción de la vida de los integrantes de la unidad doméstica y la reproducción ampliada de sus relaciones interdomésticas y comunitarias. Precisamente, el problema radica en la coexistencia de estas dos formas de racionalidad económica ${ }^{4}$ (social) que nos plantea el caso que nos ocupa.

Así, en el presente artículo nos proponemos discutir sobre límites de una concepción de estas iniciativas en tanto "alternativas" al sistema capitalista, pues las estructuras de la economía social y solidaria no existen escindidas de las estructuras del sistema económico capitalista. En este sentido, el análisis de

\footnotetext{
${ }^{4}$ Discutimos aquí con aquellos que retoman a Aristóteles para plantear en la economía social y solidaria la posibilidad de concreción del ideal antiguo de una libertad colectiva positiva fundada sobre la satisfacción de necesidades limitadas (crematística limitada) (Caillé, 2003).
} 
| 146 |

Economia social y solidaria:...

la moneda social constituye un elemento clave para dar cuenta de esto último, como así también, nos permitirá dar cuenta de las relaciones sociales en las cuales se enmarca su existencia.

\section{Las dos caras de la moneda}

En 1930, se implementaron miles de iniciativas de monedas complementarias en Estados Unidos, Canadá, Europa occidental y otras regiones afectadas por la crisis. Durante la década del ' 90 , en la Argentina se extendieron notablemente las redes del trueque, sustentadas en la existencia de monedas sociales.

Según Lietaer, las monedas complementarias benefician a todos, tanto a las empresas locales como a la sociedad en general. En este sentido, el autor propone la conformación de lo que denomina una Economía Integral "... la cual consiste en la convergencia de la economía competitiva tradicional, por un lado, y la economía cooperativa local, por el otro. La primera produce capital financiero; la segunda, capital social." (Lietaer, 2005:260)

Por su parte, Peixoto de Albuquerque (2004) sostiene que es preciso que la moneda social sea considerada como acciones que buscan construir relaciones más generales y universales con la vida de las personas, se trata de calificar la cooperación y la confianza existente en los grupos construyendo un instrumento de mediación que permita que las actividades económicas se diferencien y sean capaces de crear sociedades más justas y libres.

Por moneda social, en sentido lato, se entiende el instrumento fiducidiario (de confianza), utilizado por una o más personas y/o grupos(s) que ejerce(n) las funciones de unidad valorativa, que puede circular libremente en una comunidad y es aceptada como forma de pago; su valor nominal no es igual al valor intrínseco, sino que depende de la confianza de los que la reciben o utilizan, por ello no puede ser usada como instrumento de acumulación de las riquezas producidas por los individuos o la comunidad. (Peixoto de Albuquerque, 2004, p. 319) Por su parte, Orzi quien también analiza el caso en cuestión, menciona lo siguiente: 


\begin{abstract}
El Banco de Horas intenta forjar la implementación de un sistema económico alternativo administrado por las organizaciones con fines sociales, que produzca un efecto multiplicador del compromiso de los voluntarios dentro de la institución y la sociedad en su conjunto, que mejore los ciclos de consumo y producción local de recursos. (Orzi, 2008: 10)
\end{abstract}

Ambos autores, entienden por otra economía, una economía diferente a la capitalista, en la cual el trabajo y no el capital, es quien comanda el proceso de producción, distribución y consumo, es decir, lo económico conforma un tipo de relación social anclada al orden social. En este sentido, su preocupación estriba en la posibilidad de transitar, a partir de la creación de monedas sociales, hacia un camino que permita la desfetichización de la moneda. Ahora bien, encontramos que la moneda social, en tanto equivalente general que mide el valor de otras mercancías, se construye en referencia a la moneda oficial. Así, se pierden de vista las relaciones sociales de producción específicas en las que participa la fuerza de trabajo de los "socios", mas también, tanto el tiempo de trabajo como el producto de los trabajos particulares es medido según el sistema de precios del mercado formal. La convención por la cual es creada la moneda social sigue supeditada a las formas de fetichización que rigen en el sistema capitalista. No alcanzan los valores, por distintos que sean respecto de aquellos con los cuales funcionan los intercambios bajo la lógica capitalista, pues sería necesaria una auténtica autonomía en relación con esta última, lo cual resulta improbable. Por consiguiente, la economía social alberga en su seno las contradicciones del sistema capitalista sin lograr resolverlas. Se halla atravesada por distintas racionalidades de gobierno que contribuyen a perpetuar y reproducir dichas contradicciones. La utopía como salvación y la salvación como esperanza, se apropia y resemantiza las resistencias y conflictos. Si bien, Plasencia sostiene que “... si la función de medida de valor la ejerce la moneda de curso legal, los precios relativos de los bienes, dentro de los mercados solidarios, no se diferenciarán significativamente de los de la economía formal" (Plasencia, 2008, 
p. 46); parece que aquí subyace la idea de que los valores, propios de la gestión colectiva de la moneda social, podrían plantear una superación del problema. Contrariamente a esto último, pensamos que los valores resultan insuficientes cuando las prácticas concretas se anclan en la relación entre la economía social y solidaria con el mercado formal, los organismos de financiamiento nacional e internacional, público y privado.

Frente a las posturas mencionadas, trataremos de dar cuenta, entre otras cuestiones sobre este punto, que la retribución del trabajo de los "socios" con moneda social, permite su permanencia en tanto productores y consumidores dentro del mercado formal, prescindiendo de los costos de una relación salarial. De este modo, se garantiza la continuidad del mercado capitalista.

El Banco de Horas creó su propia moneda social (Soles), la cual media en todos los intercambios realizados en él. Sin embargo, en el marco de una organización económica que pretende alejarse de los principios mercantiles, pues al parecer no existe acumulación o búsqueda de beneficios, los precios de las mercancías se rigen, paradójicamente, por el mercado formal. Asimismo, encontramos que las relaciones sociales de producción son diferentes en el marco de la economía solidaria. Por consiguiente, podemos pensar que es posible la existencia de desigualdad en los intercambios puesto que si el respaldo de la moneda social es el trabajo humano, entonces, ninguna mercancía o servicio ofrecido es intercambiado por una mercancía (moneda) equivalente a las materias primas y/o al trabajo desembolsadas por el productor. De este modo, estaría siempre recibiendo menos de lo que da, lo cual a su vez, propicia posibilidades desiguales de consumo. En este sentido, la existencia de una moneda propia sigue albergando las desigualdades que impone el mercado capitalista, pues éste continúa siendo el principal condicionante a la hora de establecer formas de producción, intercambio y consumo. Sumado a esto último, la moneda nacional es usada como valor de referencia (un Sol igual un Peso). El camino hacia la desfetichización de la moneda, en tanto mercancía, se torna difícil de transitar si tenemos en cuenta que ambas persisten bajo la lógica del capital. 
Ahora bien, respecto del respaldo de la moneda social en el Banco de Horas, encontramos el siguiente planteo:

(...) Se podría pensar que la existencia de ciertas monedas con respaldos "fuertes" (como el oro o las divisas extranjeras) señala la poca confianza que cada integrante de la comunidad emisora tiene acerca de su reproducción. Señalan, en definitiva, el grado de injusticia y violencia sobre el que se basa el orden establecido. (Plasencia, 2008, p. 54)

Esta cita se refiere al respaldo que poseen los soles (el trabajo de los "socios", las donaciones en especie, los productos de las micro-empresas ${ }^{5}$ asociadas al Banco, la capacidad productiva de los "socios" y los servicios educativos). Sin embargo, pensamos que, en este caso, el respaldo precisamente actúa generando un sentido de obligación que sostiene la continuidad del compromiso y lo refuerza, pues se trata de sus propias capacidades de trabajo y del producto que resulta de las mismas, las que permiten la existencia de la moneda social. En cambio, las desigualdades del orden social dominante se expresan en lo que planteábamos más arriba.

Precisamente, la existencia de una moneda social y la doble participación de los "socios" tanto en el mercado formal como en el "mercado solidario", propicia lo que entendemos por doble racionalidad económica (Landaburu y Presta, 2007). Con esta noción nos referimos a la coexistencia contradictoria, en determinados grupos sociales, de dos formas distintas de racionalidad. En el caso del Banco de Horas, una racionalidad del "don" y una racionalidad empresaria (capitalista), las cuales suponen modos de pensar y actuar radicalmente diferentes. Uno de los puntos más importantes es que ambas racionalidades tienen como eje central

\footnotetext{
${ }^{5}$ Discutimos aquí con aquellos que retoman a Aristóteles para plantear en la economía social y solidaria la posibilidad de concreción del ideal antiguo de una libertad colectiva positiva fundada sobre la satisfacción de necesidades limitadas (crematística limitada) (Caillé, 2003).
} 
una lógica de intercambio que se distingue por los fines que se propone. Pero el problema surge cuando los medios que sirven a una, son utilizados para alcanzar los fines de la otra. Aquí, las prácticas se definen por su carácter tanto intencional como no intencional, siendo que la racionalidad del don es dependiente de la racionalidad capitalista, lo cual complejiza aún más el análisis. Asimismo, es importante tener en cuenta que la pluralidad de bases económicas (Comas D' Argemir, 1998) presente en las unidades domésticas contempladas, sirve de sustento a la existencia de esta doble racionalidad económica. Al estar vinculados con diferentes relaciones de producción, los miembros de estas unidades desarrollan diferentes prácticas que se articulan entre sí y que, asimismo, implican construcciones específicas respecto de la realidad. Ahora bien ¿Cómo es posible la existencia de dicha doble racionalidad económica? Podemos decir que, en los "socios", prima el deseo vinculado a la necesidad de desarrollar sus capacidades de trabajo, acompañada por una representación del mercado capitalista signada por sus aspectos negativos y disgregadores. Dicha necesidad aparece, asimismo, debida a que los integrantes del Banco de Horas no han logrado poseer un empleo estable hace largo tiempo. Las transformaciones en el mercado formal de trabajo en la zona, ha dejado sin oportunidades concretas de inserción laboral a una parte considerable de la población. Sin embargo, se expresa una contradicción, pues este trabajo humano que pretende emanciparse de la hegemonía del mercado, busca incrementar constantemente el modo de participar en el mismo. Paradójicamente, en tanto espacio de mayores oportunidades de acrecentar el alcance de dichas capacidades de trabajo y la inserción de sus productos ${ }^{6}$, más también, como fuente de reconocimiento social más amplio. Los "socios" conciben su trabajo como emancipado, incorporándolo a una lógica del don y lo que ello implica (así niegan al trabajo asalariado como única

\footnotetext{
${ }^{6}$ En esta instancia, actúan como "pequeños empresarios", elaborando estrategias de negocios, captando posibles clientes, lo cual se desarrolla aún más en el marco de los emprendimientos en el marco del Banco de Horas.
} 
forma posible del trabajo humano) pero, al mismo tiempo, dicho trabajo se extiende en sus relaciones y participación en el mercado formal (así, también, niegan el carácter de su concepción de trabajo emancipado de las relaciones de mercado). De esta manera, los sujetos se recrean a sí mismos, finalmente, a partir de un proceso de negación de sí mismos, pues es en dicha contradicción que nace la doble racionalidad económica como síntesis de los procesos de construcción de subjetividades. Síntesis sin superación, pues la contradicción permanece e implica una relación de subordinación que se manifiesta en la existencia de una doble racionalidad económica. De modo tal que se niegan a sí mismos en tanto contradicen, constantemente, los principios sobre los cuales se afirman su discurso y sus prácticas. Más también, a partir de lo antedicho, vemos cómo las formas ideológicas dominantes, con sus concepciones de trabajo y sujetos "productivos y dignos" para la sociedad, atraviesa los deseos, ya que estos son construidos siempre sobre los cimientos de los procesos históricos que abarcan a sujetos concretos a lo largo de sus vidas.

El carácter ambiguo, omnipotente y alienante de la moneda en el contexto del capitalismo moderno, advierte la cosificación de las relaciones sociales como consecuencia de una existencia regida por el afán de lucro. No obstante, en el ámbito de la economía social y solidaria, consideramos que no es necesario analizar si la moneda es algo negativo o positivo ya que eso no nos llevaría muy lejos. Mas sí creemos importante referirnos a la construcción de las relaciones sociales que avalan su existencia, para lo cual es necesario centrarnos en las percepciones de los "socios" sobre la moneda social. No obstante, debemos tener siempre presente la contradicción que constituye el hecho de que el valor de dicha moneda se halla establecido por la moneda oficial y los precios que rigen el mercado formal. Aún así, ésta puede adquirir un sentido diferente, según los entrevistados, “... nadie trata de embromar a nadie, ni de venderle más caro una cosa a otro y se generan muchos lazos de solidaridad, que pasan más allá del intercambio puramente comercial." (Socia Área de Extensión del Banco de Horas Local). 
| 152 |

Economia social y solidaria:...

Contrariamente a la racionalidad económica capitalista, la moneda social no se invierte con el fin de sacar provecho para maximizar beneficios sino que se corresponde a una racionalidad enmarcada en una ética propia de la institución en la cual circula. Consideremos el siguiente testimonio:

Yo creo que son muchas las ventajas [de la moneda
social] porque es una manera de que la gente pueda
acceder a cubrir sus necesidades directamente con sus
capacidades. Porque en una sociedad donde si vos
no tenes dinero, no existís y no podes acceder a un
montón de cosas, digamos, este sistema económico te
da la posibilidad de poder acceder dignamente a tus
cosas, a lo que vos necesitas. (Socio, tallerista)

Contra cualquier forma de asistencialismo, se enfatiza la revalorización de las capacidades de trabajo que excluye el mercado formal. El significado del trabajo se construye en relación con su carácter participativo, creativo y orientado a una causa común. Sin embargo, en el marco del Banco de Horas, según sean las capacidades y necesidades de un "socio", este puede generar más soles que otros. Si un producto / servicio no logra venderse, los "socios" tienen que cambiar sus productos / servicios hasta que las posibilidades de venta se concreten. Si tenemos esto en cuenta, podríamos pensar que la valorización de las capacidades de trabajo no es homogénea, por lo tanto, podría existir un desfasaje entre las oportunidades de consumo de unos "socios" y otros. Cada dos meses se realiza una observación al "socio" para saber si su certificado no salió al mercado con el propósito de que lo renueve por otro producto o servicio. Pasados cuatro meses, aquellos "socios", cuyos productos / servicios no son valorados por la demanda del mercado solidario, deben realizar una inversión mucho mayor que el resto, la cual podría o no ser compensada por los intercambios futuros.

Asimismo, para que las relaciones sociales basadas en la solidaridad en tanto, como dicen los "socios", "hacer propia la 
causa del otro", mantengan su continuidad, es preciso que las representaciones que las constituyen se comuniquen de generación en generación, de los "socios" viejos a los "socios" nuevos. En este sentido, el Banco de Horas posee capacitaciones para los "nuevos" en las cuales se transmiten las ideas que legitiman las prácticas llevadas a cabo, las cuales son interpretadas para construir el sentido de las mismas. Aquí, la importancia de la moneda social no se refiere a la posibilidad de su acumulación sino a la posibilidad de mantener determinadas relaciones sociales que permiten la reproducción del grupo y su vínculo con la comunidad a la cual pertenecen.

Si bien, la mayor parte de los "socios" compra una parte de las materias primas necesarias para elaborar sus productos en el mercado formal, varios de ellos obtiene lo necesario en el Banco de Horas a través de los llamados "insumos estratégicos" adquiridos por el Banco (harina, huevos, verduras, etc.) con el dinero (pesos) que algunos "socios" pagan por productos / servicios en lugar de hacerlo con "soles". Algunas "socias" nos comentaron que no se rigen por los precios del mercado sino que el precio de sus productos lo establecen basándose en el gasto de materias primas para su producción. Una de ellas, dijo que muchos "socios" calculan los precios sumándole al costo de las materias primas un $200 \%$ más. Además de ofrecer sus productos en el Banco de Horas, varios "socios" los venden en el mercado local a cambio de pesos. Sin embargo, la Coordinación del Banco de Horas reafirma que los precios tienen como única referencia los valores del mercado. Uno de los "socios" comentaba que los precios de sus productos (y también del resto de los "socios") son iguales o menores a los del mercado y agrega que guiarse por éste genera estabilidad en los precios en la institución: "el Banco de Horas provee herramientas para que, de alguna manera, haya una estabilidad, aunque sea mínima..." (Socia del Banco de Horas)

Durante una de las entrevistas, una de las "socias" (B socia de la comunidad) habló de una falta de circulante (moneda social). Ella ofrece budines y ropa reciclada y es capaz de generar muchos "soles" debido a que sus productos poseen una demanda 
importante. No obstante, se queja de la limitación que encuentra pues, según su criterio, no emiten suficiente moneda. Nos aclaró que aún no lo había hablado con la coordinadora. Frente a esta inquietud, preguntamos en la Coordinación del Banco de Horas si había algún problema con la falta de circulante. La coordinadora nos respondió que justamente la pregunta apuntaba a un "tema complicado". Según ella, se quejan sólo quienes no venden sus certificados de trabajo y no se ocupan por cambiarlos por otros. Curiosamente, tomó a " $\mathrm{B}$ " como ejemplo de una socia que, al generar muchos "soles", no se queja. Ahora bien, existe un problema que subyace a esta "falta de circulante", es decir, existe una importante deuda en "soles" por parte de los "socios" que no se preocupan por renovar sus certificados de trabajo que no son intercambiados y, así, producir "soles" que mantengan el dinamismo de los circuitos de intercambio. Por tanto, si escasean los soles, es debido al debilitamiento del trabajo de los "socios" en determinados períodos lo cual, a su vez, merma el respaldo de la moneda social. Precisamente, el presidente del Banco de Horas, mencionó en una de las entrevistas, que una de las dificultades es que "hay buenas cosas pero no están saliendo tanto o tan rápido". Esto último, genera preocupación en los "socios" ya que si no venden, se vencen los certificados de trabajo. Sin embargo, también consideró que, debido a la incorporación de los nuevos "socios", hay más demanda y, por lo tanto, más circulación. Si el respaldo de la moneda es, principalmente, el trabajo de los "socios", entonces, el crecimiento de esta deuda podría estar provocando una relativa falta de moneda circulante. Es por tal razón, también, que la Coordinación enfatiza en la necesidad de no "estancar" la moneda, es decir, mantenerla siempre en circulación y no acumularla con el propósito de no "trabar" los intercambios. Asimismo, esto último expresa otro aspecto importante, a saber: el posible debilitamiento del compromiso social de los "socios". En este sentido, comentaban que si bien existe un proceso de cambio de mentalidad, aún no está completo. A la vez que resaltan las distintas formas de solidaridad, también se mencionan que todavía falta tiempo para consumar dicho proceso. 


\begin{abstract}
Las dificultades que acá hay muy buenas cosas pero no están saliendo tanto o tan rápido. Los socios dicen "Uy!" Se ve en la problemática de tener que vender sus productos porque sino se les vence el cheque y entonces las rupturas en los compromisos son más fáciles. (Presidente Banco de Horas)
\end{abstract}

No basta decir que la racionalidad económica de los "socios" del Banco de Horas apunta a la satisfacción de las necesidades materiales según los requerimientos institucionales basados en la reciprocidad y no sobre la maximización de los beneficios individuales, pues puede suceder también que, a veces, ambas instancias no se excluyan mutuamente. En Godelier (1974) encontramos que en los sistemas de precios debe existir una coincidencia entre el valor de las mercancías y la necesidad social solvente. Si la oferta se planifica en función de la demanda, se logrará una optimización de las capacidades sociales. En este sentido, es importante conocer la jerarquía de las necesidades sociales, es decir, dar cuenta de las características de la demanda social. Probablemente, podríamos pensar que los precios del Banco de Horas tendrían que establecerse en relación inversa a la necesidad social (mayor necesidad social de determinadas mercancías igual a un menor precio/ menor necesidad social de determinadas mercancías igual a un mayor precio). La lógica instrumental del sistema de precios del mercado capitalista se rige por un criterio de escasez, a partir del cual esto sucede al contrario de esto último, pues el aumento de la demanda implica la posibilidad de incrementar los precios de las mercancías. Ahora bien, si el Banco de Horas, el cual se sustenta sobre la base el requerimiento de distintas formas de reciprocidad, retoma, como hemos dicho anteriormente, la lógica de oferta/demanda del mercado formal, entonces, las desigualdades propias de éste último tienen más posibilidades de trasladarse al primero.

En este sentido, tenemos que: 
$|156|$

Economia social y solidaria:...

La moneda no es de ningún modo un hecho material y físico, sino que es, esencialmente un hecho social, su valor reside en su poder de compra, y en la medida de la confianza que se ha depositado en ella. Estamos hablando del origen de una noción, del origen de una institución, en una palabra, de una fe. (Mauss, 1971, p. 87)

¿Podemos afirmar que por el simple hecho de ser una moneda paralela o social su poder es nulo o inexistente? Aún, Mauss, al referirse a la moneda en la economía del don, menciona su capacidad para dirigir a los demás. Luego, se pregunta respecto de la confianza en el dinero "¿Acaso no reside en la creencia de que, gracias a él, podremos obtener de nuestros contemporáneos las prestaciones - en materia o en servicios - que nos permita exigirles la situación del mercado?" (Op. cit.: 91-92).

En Mauss, podemos encontrar que la moneda es parte del don. Una "socia" nos comentaba que "estas todo el tiempo confundiéndote, sobretodo acá porque decís pesos todo el tiempo y son soles". De este modo, podríamos concluir que se trata de distintos usos de moneda, complementarios y coexistentes. Sin embargo, a nuestro entender, la contradicción prevalece. El Banco de Horas existe a partir de una relación dialéctica con el sistema capitalista. Ahora bien, una explicación sobre los diferentes usos de la moneda no alcanzaría ya que las relaciones de poder que se construyen a partir de las distintas lógicas de intercambio (mercantil / don), se encuentran en constante tensión. De hecho, como hemos mencionado anteriormente, las relaciones de poder del mercado formal condicionan el funcionamiento de los intercambios dentro del Banco de Horas. Podemos pensar que la doble racionalidad de los sujetos coexiste pero siempre en contradicción debido a que la construcción de una racionalidad (don) depende de la otra (empresarial).

La invención de la moneda alberga las contradicciones que plantean las relaciones sociales que se entablan a partir de las distintas lógicas de intercambio. Coexisten en ella y se convierten en su símbolo. Al externalizarse de los sujetos, quedan aliviados 
de toda responsabilidad, la cual se traslada y se deposita en la moneda. Así, ésta se transforma en culpable de todos los pesares y alegrías. Es este tipo de fe o creencia - volviendo a la cita anterior de Mauss (1979) - en la moneda, la que termina por contribuir, al menos en parte, a la existencia de una doble racionalidad.

\section{Consideraciones finales}

La creación de una moneda social constituye una actualización y reinterpretación de prácticas y significados que ha acompañado a los "socios" a lo largo de sus vidas, los cuales se inscriben ahora en la doble estructuración de su racionalidad económica (social). La importancia de la moneda social radica, entonces, en la posibilidad de construir y reconstruir determinadas relaciones sociales que permiten la reproducción del grupo social y su vínculo con la comunidad. Asimismo, al ser su respaldo, principalmente, el trabajo de los "socios", contribuye a sostener el compromiso que los une.

La función económica de la moneda social es indisociable de su función social y cultural. En el Banco de Horas, la moneda produce / reproduce las relaciones sociales basadas en la donación de tiempo de trabajo (racionalidad del don). Sin embargo, al mismo tiempo que hace esto último, su existencia reproduce la violencia que encierra la moneda en el mercado formal, pues la moneda que han creado se halla supeditada al sistema de precios del mercado capitalista y oscurece las relaciones de producción específicas de la economía solidaria. Podemos decir que dichas desigualdades quedan resignificadas por la categoría de don como eje central de los intercambios en el Banco de Horas. Por consiguiente, la moneda social, en tanto valor de medida homogéneo, omite la heterogeneidad tanto de los productos como de los procesos de trabajo.

Lo que se plantea es la existencia de una racionalidad dominante (capitalista) y distintas racionalidades subordinadas contrapuestas que se desarrollan dentro de los límites cambiantes 
que le impone la primera, por lo cual su potencial va a ser reducido por no tener la posibilidad de socavar por completo los condicionantes estructurales. Asimismo, esto conduce al intento de remediar la incertidumbre y el conflicto con un orden ficticio y naturalizado de las cosas. En el caso de las instituciones de la economía social y solidaria, la creencia en la autodeterminación es crucial para la persistencia de una doble racionalidad económica. Al permitir y apoyar la existencia de racionalidades, consideradas "alternativas" por los propios sujetos, éstas terminan por convertirse en parte de las estrategias disciplinadoras del capital.

Promulgando un discurso no consumista y contrario a la racionalidad instrumental del capitalismo, los sujetos que construyen estas iniciativas, paradójicamente, continúan vinculándose como consumidores en el mercado capitalista. Por consiguiente, los deseos y aspiraciones de una clase trabajadora cuyas capacidades trabajo ya no eran requeridas formalmente por el sector empresarial, concentraba un potencial social que no tardaría en ser reincorporado en la agenda del Estado y el sector privado. Las alianzas entre sectores se consolidaron y, pronto, aquello que había surgido como un posible foco de resistencias y conflictos fue resignificado en función de nuevas relaciones de poder. La organización del Estado se ajustó a la lógica empresarial y su discurso, iniciando la supuesta "modernización" del mismo, para facilitar la implementación de las políticas de desarrollo económico previstas para la economía social y solidaria. Políticas que encierran una nueva forma de extender los intereses de los agentes del capital hacia todos los ámbitos de la sociedad.

\section{Bibliografia}

CAILLÉ, A. Sobre los conceptos de economía en general y de economía solidaria en particular. L' alter-économie. Quelle “autre mondialiation? In. Revue MAUSS, no 21, 2003 
COMAS D' ARGEMIR, Dolors. Antropología Económica. Barcelona: Ariel, 1998.

CORAGGIO, J. L. La Economía Social como vía para otro desarrollo social. http://www.urbared.ungs.edu.ar, 1992.

GODELIER, M. Racionalidad e irracionalidad en economía. México: Siglo XXI, 1974.

LANDABURU, L y PRESTA, S. Elementos para la reflexión en torno al concepto de unidad doméstica en el contexto neoliberal. In. Revista Papeles de Trabajo № 14 Universidad Nacional de Rosario, 2007

LIETAER, B. El futuro del dinero. Cómo crear nueva riqueza, trabajo y un mundo más sensato. Buenos Aires: Errepar / Longseller, 2005.

MAUSS, M. Institución y cultos. Representaciones colectivas y diversidad de civilizaciones. In. Obras II. Barral Editores: Barcelona, pp. 87-127, 1971.

MAUSS, M. Sobre los dones y sobre la obligación de hacer regalos. En: Sociología y Antropología. Madrid: Editorial Tecnos, 1979.

PEIXOTO DE ALBUQUERQUE, P. Moneda social 2. En: Cattani, A. D. (Org.) La Otra Economía. Buenos Aires: Altamira, 2004.

PLASENCIA, A. y ORZI, R. Moneda social y mercados solidarios. Buenos Aires: Editorial Ciccus, 2007

PRIMAVERA, H. Moneda Social 1. En: Cattani, A. D. (Org.) La Otra Economía. Buenos Aires: Altamira, 2004. 